\title{
The role of the bacterial microbiome in the treatment of cancer
}

\author{
Zi-Kun Yu $u^{1,2+}$, Rui-Ling Xie ${ }^{1,2+}$, Rui You ${ }^{1,2+}$, You-Ping Liu ${ }^{1,2}$, Xu-Yin Chen ${ }^{1,2}$, Ming-Yuan Chen ${ }^{1,2^{*}}$ and \\ Pei-Yu Huang ${ }^{1,2^{*}}$ (D)
}

\begin{abstract}
The human microbiome is defined as the microorganisms that reside in or on the human body, such as bacteria, viruses, fungi, and protozoa, and their genomes. The human microbiome participates in the modulation of human metabolism by influencing several intricate pathways. The association between specific bacteria or viruses and the efficacy of cancer treatments and the occurrence of treatment-related toxicity in cancer patients has been reported. However, the understanding of the interaction between the host microbiome and the cancer treatment response is limited, and the microbiome potentially plays a greater role in the treatment of cancer than reported to date. Here, we provide a thorough review of the potential role of the gut and locally resident bacterial microbiota in modulating responses to different cancer therapeutics to demonstrate the association between the gut or locally resident bacterial microbiota and cancer therapy. Probable mechanisms, such as metabolism, the immune response and the translocation of microbiome constituents, are discussed to promote future research into the association between the microbiome and other types of cancer. We conclude that the interaction between the host immune system and the microbiome may be the basis of the role of the microbiome in cancer therapies. Future research on the association between host immunity and the microbiome may improve the efficacy of several cancer treatments and provide insights into the cause of treatment-related side effects.
\end{abstract}

Keywords: Gut microbiome, Locally resident microbiome, Intratumour microbiota, Cancer treatment, Mechanism, Future research

\section{Background}

The human microbiome can be considered an organ of the human body and is defined as the microorganisms that reside in the human body, such as bacteria, viruses, fungi, and protozoa, and their genomes [1]. Recently, the relationship between the human microbiome, especially the gut microbiome, and human disease has attracted increasing attention. Probiotics, defined as "live microorganisms that, when administered in adequate amounts, confer a health benefit on the host [2], have been shown to

\footnotetext{
* Correspondence: chenmy@sysucc.org.cn; huangpy@sysucc.org.cn

${ }^{\dagger}$ Zi-Kun Yu, Rui-Ling Xie and Rui You contributed equally to this work. 'Department of Nasopharyngeal Carcinoma, Sun Yat-sen University Cancer Center, 651 Dongfeng East Road, Guangzhou 510060, People's Republic of China

Full list of author information is available at the end of the article
}

participate in the modulation of human metabolism by influencing several intricate metabolic pathways [3]. The gut microbiome is an indispensable part of the human microbiome and refers to the enormous number of microorganisms resident in the gastrointestinal tract. Dysbiosis of the gut microbiome, in which there are abnormalities in the types and number of organisms present in the natural microflora of the host, has been shown to be associated with digestive, neurologic, metabolic, respiratory and several other illnesses $[4,5]$. Cancer is a leading cause of death worldwide [6]. The development of some cancers has been found to be associated with specific bacterial or viral infections [7-12]. Moreover, researchers have found that the treatment-related toxicity of cancer therapy can be mediated by different constituents of the human

(c) The Author(s). 2021 Open Access This article is licensed under a Creative Commons Attribution 4.0 International License, which permits use, sharing, adaptation, distribution and reproduction in any medium or format, as long as you give appropriate credit to the original author(s) and the source, provide a link to the Creative Commons licence, and indicate if changes were made. The images or other third party material in this article are included in the article's Creative Commons licence, unless indicated otherwise in a credit line to the material. If material is not included in the article's Creative Commons licence and your intended use is not permitted by statutory regulation or exceeds the permitted use, you will need to obtain permission directly from the copyright holder. To view a copy of this licence, visit http://creativecommons.org/licenses/by/4.0/ The Creative Commons Public Domain Dedication waiver (http://creativecommons.org/publicdomain/zero/1.0/) applies to the data made available in this article, unless otherwise stated in a credit line to the data. 
microbiome [13-16]. A series of studies have demonstrated that the gut microbiota can influence the host immune response to tumours and strongly affect the response to cancer treatment, especially immune checkpoint blockade, in both clinical cohorts and mouse models [17-26]. Additionally, the association between locally resident microbiota or intratumour microbiota and carcinogenesis and the effect of cancer therapy is a current focus of microbiome research. The locally resident microbiota is likely to be another useful prognostic factor for cancer patients [11, 27-29]. However, understanding of the association between the host microbiome and the cancer treatment response is limited to specific cancers, suggesting the necessity of research into this association in other cancer types. Several cancers and treatments have been found to be influenced by the microbiome, especially the bacterial microbiome, by next-generation sequencing, which helps identify the species and quantity of these microorganisms. A timely update and summary of the developments in research into the microbiome and cancer treatment are necessary to promote future studies. Although some reviews have covered the role of the human microbiome and cancer treatment $[25,30]$, there is still no clear direction for future research. With the development of knowledge of the microbiome, more detailed mechanisms and methods to modulate the microbiome have been revealed, which need to be summarized and applied in future research. Herein, we attempted to determine future direction of research in this field and develop a plan for future research by studying the functions and mechanisms of the host microbiome. A comprehensive literature search was performed to identify, collate and analyze previously published research. Studies published before November 2020 were included if they were identified by the search strategy and met the selection criteria. The literature search was conducted using the PubMed, Web of Science, Embase and Cochrane databases, and search terms used were "cancer", "treatment response", and "microbiome". Only studies on bacterial microbiota were included and discussed in our review. The reference lists of the included papers and review articles were also searched. We discuss the most recent reports, in particular a breakthrough report on the association between the microbiota and several cancer therapies, to explore the potential role of the gut microbiota and locally resident microbiota in cancer therapy. The reported mechanisms of this relationship, such as metabolism, the immune response and the translocation of the microbiome, is also discussed to promote future research into this association in other cancer types.

\section{Microbiome and cancer therapy}

Research into the molecular mechanisms of carcinogenesis and the progression and metastasis of cancer has yielded several cancer therapies, such as surgery, radiation therapy, chemotherapy, targeted therapy, immune checkpoint blockade and hormone therapy. Researchers believe that cancer can arise due to the attenuation of immunosurveillance and the development of immunological tolerance to tumour-derived antigens [31]. Several studies have shown that the gut microbiota can modulate the host immune response to tumours [17]. The potential role of the gut microbiota as a biomarker for predicting the efficacy of cancer treatment has attracted the interest of clinical researchers. For locally resident microbiota, many studies on the complex interaction between the gut and locally resident microbiota have recently shown that locally resident microbiota can be a prognostic factor of cancer treatment [11, 27-29]. Herein, we separately discuss the impact of the locally resident microbiota and the gut microbiome on cancer and cancer therapy.

\section{Cancer therapy and the gut microbiome}

\section{Immune checkpoint inhibitors (ICls)}

The utilization of immune checkpoint inhibitors (ICIs) in cancer treatment, including monoclonal antibodies targeting the programmed death receptor (PD-1), ligand of programmed death receptor (PD-L1) and cytotoxic T lymphocyte-associated protein 4 (CTLA-4) receptor, is considered a revolution in cancer therapy that changes the poor prognosis of many malignancies and is widely used in the treatment of advanced-stage cancer [32-39]. However, primary and secondary resistance to cancer treatment can seriously influence patient outcomes and remains a challenge [40]. Recently, the gut microbiota was found to have a strong impact on tumour response to ICIs in both clinical cohorts and preclinical mouse models [18-26]. Some of the earliest work on the influence of gut microbes on the efficacy of ICIs for several cancers was performed in preclinical mouse models $[22,41]$. Researchers have demonstrated that tumours of the same mouse strain purchased from different suppliers with different gut microbiomes have distinct responses to ICIs that target PD-1 for melanoma [22]. Another study was conducted to test whether the relationship between the response to CTLA-4 monoclonal antibodies and the gut microbiome was the same as that in anti-PD1 therapy and it was found that Bacteroidales play a key role in the effects of tumour immunity induced by the blockade of CTLA-4 [41]. In these studies, mice with a "favourable" gut microbiome had a better response, which may result from the enhancement of the $\mathrm{T}$ cell response via the activation of antigen presenting cells (APCs), such as dendritic cells.

Recent clinical studies also suggested that dysbiosis of the gut microbiome can induce resistance to ICIs, highlighting the distinct role of the gut microbiome in regulating ICI efficacy and side effects [13, 19-21]. 
Subsequent research on the relationship between immune checkpoint blockade and the gut microbiota concentrated on faecal microbial transplantation (FMT) in murine models to verify the results from human studies $[18,20]$. Studies on the association between different gut microbiomes and the efficacy of cancer immunotherapy are summarized in Table 1. Bacteroidetes was found to be a biomarker of nonresponders to immune checkpoint inhibitors in metastatic melanoma (MM) patients in several studies $[13,14,20,41]$ and may decrease the response rate and attenuate systemic and antitumour immunity, leading to a decreased risk for local inflammation, such as ICI-induced colitis. Nevertheless, some Bacteroidetes, such as Bacteroides thetaiotamicron and $B$. caccae, are associated with an effective therapeutic response [21, 22, 41]. Faecalibacterium, Bifidobacterium and Ruminococcaceae can improve the therapeutic response to ICIs, while Faecalibacterium and other Firmicutes may lead to a higher risk for ICI-induced colitis $[18,19,21,24]$. In non-small-cell lung cancer (NSCLC) and renal cell carcinoma (RCC), Akkermansia muciniphils and Alistipes are markers ICI responders [18]. Pretreatment antibiotics (ATBs) have been found to have a negative impact on ICI efficiency due their impact on the diversity of the gut microbiome and lead to secondary dysbiosis [18, 43, 44]. For instance, Routy [18] found that progression-free survival (PFS) and overall survival (OS) times were significantly shorter in a group of patients treated with ATBs for NSCLC, RCC and urothelial carcinoma (UC) and anti-PD1-based immunotherapy. The median PFS and OS times for the ATB group were 3.5 months and 11.5 months, respectively, while the median PFS and OS times for patients who did not receive ATBs were 4.1 months and 20.6 months, respectively $(p=0.017$ for PFS and $p<0.001$ for OS). These studies suggest a strong correlation between the intestinal flora and the efficacy of tumour immunotherapy.

Some of the previously published studies identified the same "favourable microbiota" indicative of ICI responsiveness. However, the "favourable microbiota" changes depending on cancer type, suggesting that different tumours may have different "favourable microbiota". The distinct effect provided by the same microorganisms on the same ICIs is likely have been identified due to sequencing techniques, which can demonstrate the different functions of bacteria based on detailed classification approaches. Further research on other cancer types should be conducted to further reveal the relationship between the gut microbiome and ICI efficacy.

\section{Chemotherapy}

Cancer chemotherapy, defined as treatment with traditional cytotoxic chemotherapeutic agents, has been proven to be influenced by the gut microbiome in murine models, especially therapies with cyclophosphamide (CTX) and oxaliplatin [23, 24, 45]. The effects of cyclophosphamide are partially based on mediation of the antitumour immune response [46]. A previous study showed that the composition of the gut microbiota can be modified by cyclophosphamide, which causes some gram-positive bacteria to translocate into the secondary lymphoid organs, prompting the production of "pathogenic" $\mathrm{T}$ helper 17 (pTh17) cells and enhancing the response of the host immune system caused by memory $\mathrm{T}$ helper 1 (Th1) cells [23]. The results of this study highlighted the important role of the gut microbiome in cancer immunity and the complicated interaction between the microbiome and chemotherapy [23]. A further study revealed that two specific species in the gut microbiome, Enterococcus hirae and B. intestinihominis, can influence the clinical benefits of CTX for cancer treatment by reducing regulatory $\mathrm{T}$ cells and enhancing the immune response of MHC class I-restricted cytotoxic T cells (CTLs) to the tumour, which eventually alters the tumour microenvironment [45]. Another study demonstrated that commensal bacteria modulate the genotoxicity of platinum compounds by increasing reactive oxygen species (ROS) levels [24]. Recent studies have indicated that resistance to cytotoxic chemotherapeutic agents combined with oxaliplatin and capecitabine in colorectal cancer patients can be enhanced by Fusobacterium nucleatum resident in the gut [47]. Consequently, "pharmacomicrobiomics" is an emerging discipline in chemotherapy research [48]. In regard to the side effects of chemotherapy, researchers have found that intestinal microbiota can modulate the adverse drug response of irinotecan-based chemotherapy by reactivating the metabolite of SN-38 glucuronide [49]. In this study, the abundance of Faecalibacterium prausnitzii and specific species of Bacteroides were significantly different between different cohorts stratified by the metabolism of glucuronide. Inhibiting microbial $\beta$-glucuronidases may decrease the serious side effects caused by irinotecan, such as severe diarrhoea, in specific cohorts. Another study on the FOLFOX chemotherapy regimen (5-FU, leucovorin calcium and oxaliplatin) in a colorectal cancer model demonstrated that some microbiome compositions can induce the activation of nuclear transcription factor- $\mathrm{kB}(\mathrm{NF}-\mathrm{kB})$ and increase the production of interleukin-6 (IL-6) and tumour necrosis factor (TNF), which promotes inflammation and causes mucosal damage [50]. However, the probiotic Lactobacillus rhamnosus can help reduce the mucositis induced by chemotherapy by modulating the proinflammatory response and suppressing intrinsic apoptosis in intestinal injury [50]. In general, the aforementioned studies show that the gut microbiome can influence the efficacy of chemotherapy by modulating host immunity, suggesting 
Table 1 Clinical and preclinical studies about the association between gut microbiome and the host response to immune checkpoint inhibitors sorted by the category of bacteria

\begin{tabular}{|c|c|c|c|}
\hline $\begin{array}{l}\text { Gut } \\
\text { microbiome } \\
\text { categories }\end{array}$ & Mice model, or patients & Impacts & References \\
\hline $\begin{array}{l}\text { Bacteroidetes } \\
\text { Bacteroides }\end{array}$ & $\begin{array}{l}\text { Antibiotic-treated or germ-free mice with MCA205 } \\
\text { sarcomas receive Anti-CTLA-4(Ipilimumab) therapy }\end{array}$ & Improved response and reduced colitis & $\begin{array}{l}\text { Vetizou et al. } \\
\text { (2015) [41] }\end{array}$ \\
\hline
\end{tabular}

Bacteroides

B. fragilis

B.

thetaiotaomicron

B. caccae

Bacteroides

thetaiotamicron

Bacteroidales

MM patients receive Anti-CTLA-4(Ipilimumab)

Reduced the risk of $\mathrm{ICl}$ induced colitis

Dubin

therapy

Adult MM patients receive Ipilimumab, Nivolumab Ipilimumab plus nivolumab, pembrolizumab (Anti-CTLA-4 or Anti-PD-1 or combination of AntiCTLA-4 and Anti-PD-1 therapy)

MM patients receive Anti-CTLA-4(Ipilimumab) therapy

MM patients, germ-free mice with injection of $\mathrm{BP}$ melanoma cell receive Anti-PD-1 therapy

Bifidobacterium Melanoma mice with distinct commensal B. pseudolongum microbiota receive Anti-PD-L1 therapy

B. longum

MM patients receive Anti-PD-1 therapy

germ-free or specific-pathogen-free mice with injection of MC38 colorectal cancer cells receive anti CTLA-4 treatment

Faecalibacterium and other

Firmicutes

Clostridiales

Faecalibacterium

Faecalibacterium

prausnitzii

MM patients, germ-free mice with injection of BP melanoma cell receive Anti-PD-1 therapy

Adult MM patients receive

Ipilimumab, Nivolumab

Ipilimumab plus nivolumab, pembrolizumab

(Anti-CTLA-4 or Anti-PD-1 or combination of Anti-

CTLA-4 and Anti-PD-1 therapy)

MM patients receive

Anti-CTLA-4(Ipilimumab) therapy

Ruminococcaceae MM patients, germ-free mice with injection of BP melanoma cell receive Anti-PD-1 therapy

\begin{tabular}{|c|c|}
\hline $\begin{array}{l}\text { Collinsella } \\
\text { aerofaciens }\end{array}$ & MM patients receive Anti-PD-1 therapy \\
\hline $\begin{array}{l}\text { Enterococcus } \\
\text { faecium }\end{array}$ & MM patients receive Anti-PD-1 therapy \\
\hline Isenella species & $\begin{array}{l}\text { germ-free or specific-pathogen-free mice with injec- } \\
\text { tion of MC38 colorectal cancer cells receive anti } \\
\text { CTLA-4 treatment }\end{array}$ \\
\hline $\begin{array}{l}\text { Lactobacillus } \\
\text { johnsonii, }\end{array}$ & $\begin{array}{l}\text { germ-free or specific-pathogen-free mice with injec- } \\
\text { tion of MC } 38 \text { colorectal cancer cells receive anti } \\
\text { CTLA-4 treatment }\end{array}$ \\
\hline $\begin{array}{l}\text { Holdemania } \\
\text { filiformis }\end{array}$ & $\begin{array}{l}\text { Adult MM patients receive } \\
\text { Ipilimumab, Nivolumab } \\
\text { Ipilimumab plus nivolumab, pembrolizumab } \\
\text { (Anti-CTLA-4 or Anti-PD-1 or combination of Anti- } \\
\text { CTLA-4 and Anti-PD-1 therapy) }\end{array}$ \\
\hline $\begin{array}{l}\text { Dorea } \\
\text { formicogenerans }\end{array}$ & $\begin{array}{l}\text { Adult MM patients receive } \\
\text { Ipilimumab, Nivolumab } \\
\text { Ipilimumab plus nivolumab, pembrolizumab } \\
\text { (Anti-CTLA-4 or Anti-PD-1 or combination of Anti- } \\
\text { CTLA-4 and Anti-PD-1 therapy) }\end{array}$ \\
\hline
\end{tabular}

Predicted effective therapeutic response

(2016) [14]

Frankel et al.

(2017) [21]

Bacteroides decreased therapeutic response and decrease risk of ICls-induced colitis

Chaput et al. (2017) [13]

Bacteroidales decreased response, and attenuate systemic and antitumor immunity

Gopalakrishnan et al. (2018)

[20]

Delayed melanoma growth, and enhanced CD8 + T cell priming and accumulation in the tumor

Sivan et al. (2015) [22] microenvironment

Improved therapeutic response, enhanced tumor control, and improved $T$ cell response.

Matson et al. (2018) [19]

B. pseudolongum (belongs to B. pseudolongum) enhanced Mager et al. immunotherapy response through production of the metabolite inosine

Clostridiales Faecalibacterium and Ruminococcaceae Improved response, enhanced systemic and antitumor immunity

Predicted effective therapeutic response

(2020) [42]

Gopalakrishnan et al. (2018)

[20]

Frankel et al. (2017) [21]

Faecalibacterium and other Firmicutes Improved

Chaput et al. (2017) [13]

colitis

Ruminococcaceae Improved response, and enhanced cancer immunity

Gopalakrishnan et al. (2018) [20]

Improved therapeutic response, enhanced tumor control, and improved T cell response.

Matson et al. (2018)

Improved therapeutic response, enhanced cancer immunity, and improved T cell response.

Matson et al. (2018)

Mager et al. (2020) [42] immunity, and improved $T$ cell response.

Mager et al. (2020) [42] immunity, and improved T cell response. Frankel et al. (2017) [21]

Dorea formicogenerans enriched only in patients who accepted pembrolizumab and predicted effective therapeutic response
Frankel et al (2017) [21] 
Table 1 Clinical and preclinical studies about the association between gut microbiome and the host response to immune checkpoint inhibitors sorted by the category of bacteria (Continued)

\begin{tabular}{|c|c|c|c|}
\hline $\begin{array}{l}\text { Gut } \\
\text { microbiome } \\
\text { categories }\end{array}$ & Mice model, or patients & Impacts & References \\
\hline $\begin{array}{l}\text { Akkermansia } \\
\text { muciniphil }\end{array}$ & $\begin{array}{l}\text { NSCLC and RCC patients receive Anti-PD-L1 and } \\
\text { Anti-PD-1 }\end{array}$ & Improved therapeutic response & $\begin{array}{l}\text { Routy et al. } \\
(2018)[18]\end{array}$ \\
\hline Alistipes & $\begin{array}{l}\text { NSCLC and RCC patients receive Anti-PD- } L 1 \text { and } \\
\text { Anti-PD-1 }\end{array}$ & Improved therapeutic response & $\begin{array}{l}\text { Routy et al. } \\
(2018)[18]\end{array}$ \\
\hline
\end{tabular}

Abbreviations: CTLA-4 cytotoxic T lymphocyte-associated antigen 4, MM metastatic melanomas, NSCLC non-small-cell lung cancer, UC urothelial carcinoma, PD-1 programmed cell death protein 1, PD- L1 programmed death-ligand 1, $R C C$ renal cell carcinoma

that the gut microbiome may have a different influence on different traditional cytotoxic chemotherapeutic agents because of the distinct impact of different agents on cancer immunity. Cytotoxic chemotherapeutic agents, such as cyclophosphamide, which are closely related to antitumour immune responses, may be more profoundly affected by the composition of the gut microbiome. In addition to acting as the predicting factor of chemotherapyrelated toxicity, particular microbes may become a future therapeutic target to reduce side effects, potentially improve patient compliance and consequently improving the efficacy of cancer treatment. However, more studies are necessary to further determine the association between the microbiome and cancer treatment and to investigate the potential benefits of microbiome modulation.

\section{Radiation therapy}

One of the most indispensable treatments for cancer is radiation therapy. Researchers have found that analyzing the diversity and abundance of the rectal microbiome during cisplatin and radiation therapy (CRT) can predict the clinical outcome of cervical squamous cell carcinoma (CSCC) and concluded that a specific intestinal microbiota may have a positive effect on the efficacy of the treatment, while a specific vaginal microbiota seems to negatively influence the outcome of CRT [51]. Radiotherapy can also induce apoptosis of intestinal cells and cause damage to the gut microbiome composition [52], leading to intestinal inflammation, which may cause diarrhoea and fatigue $[53,54]$. The mechanism may rely on the activation of interleukin-1B (IL-1B), which means that the blockade of IL-1B or rebuilding of the gut microbiome system can reduce the damage caused by radiation therapy [55]. A recent study showed that the side effects, such as fatigue, nausea, vomiting and diarrhoea, caused by radiation therapy can be mediated by probiotics such as Lachnospiraceae and Enterococcaceae, which means that it is likely to reduce the radiation damage caused by the therapy by modulating the gut microbiome [56]. Interestingly, the results of a randomized clinical trial revealed that the combination of probiotics with radiation therapy for patients with nasopharyngeal carcinoma receiving concurrent radiochemotherapy can significantly strengthen host immunity and alleviate the oral mucositis $(\mathrm{OM})$ associated with radiochemotherapy by modifying the gut microbiota [57]. However, there is no clear evidence that the intestinal flora can directly affect the efficacy of radiation therapy.

Although there is not enough evidence showing that the microbiome can directly impact the efficacy of radiation therapy, the association between the side effects of radiation therapy and the gut microbiome makes it possible to modulate the composition of the gut microbiome to reduce radiation therapy-related toxicity, which is likely to improve the prognosis of patients who receive radiation therapy. The mechanism of the association between the host microbiome and the response to and side effects of radiation therapy may be revealed in the future.

\section{Other therapy}

In the case of surgery, researchers have found that the gut microbiome of patients with colorectal cancer is associated with postoperative infections, anastomotic leakage and ileus [58]. Researchers have also found that the gut microbiome of long-term survivors and short-term survivors of pancreatic adenocarcinoma (PDAC) who received surgery show different compositions and abundances, which can be a predictive factor for PDAC patient survival. In addition, the transplantation of specific gut microbiomes from long-term survivors can enhance the immune response to tumours in preclinical murine models [59]. Determining whether modifying the gut microbiome before surgery can improve the prognosis of patients treated by surgery may be a future research direction.

In regard to haematopoietic stem cell transplant (HSCT), previous studies have suggested that in cases of graft versus-host disease (GVHD) induced by HSCT, the gut microbiota is an indispensable factor that can influence the development of GVHD [15, 16, 60]. Peled [60] found that a decreased risk of relapse is associated with Eubacterium limosum, while Jenq [15] found that Blautia is related to a decrease in GVHD-related mortality.

Preclinical models have shown that depleting the gut microbiota could maintain the survival of transferred $\mathrm{T}$ 
cells in a cervical cancer model treated with adoptive $\mathrm{T}$ cell therapy (ACT), which is dependent on systemic CD8 $\alpha+$ dendritic cells (DCs) and interleukin-12 (IL12, [61]). Moreover, in a murine model that received CpG oligonucleotide immunotherapy and interleukin-10 treatment, $A$. shahii was found to improve the response to the treatment [24].

Hormone therapy is also related to the gut microbiome. Sfanos [62] found that people receiving oral androgen receptor axis-targeted therapies (ATT) for prostate cancer had altered gastrointestinal microbiome composition, which may influence the clinical benefits of ATT and potentially influence the efficacy of other therapies, such as immunotherapy, by altering the gastrointestinal microbiota.

The potential clinical effect provided by the gut microbiome on therapy, such as surgery, hormone therapy, and stem cell transplant therapy, and the mechanism of the effect should be further studied in the future.

\section{The mechanism of gut microbiome-mediated influence on cancer therapy}

Mechanism which has been revealed of the association between gut microbiomes and the efficacy of cancer treatment are summarized in Fig. 1.

\section{Metabolism}

Metabolism of the host or the tumour cell is likely an indispensable factor that may alter the efficacy and side effects of chemotherapeutic agents. The gut microbiota has the potential to influence the metabolism of chemotherapeutic drugs directly or to modulate other small molecules to alter host metabolism and indirectly affect the efficacy of cancer treatment. In regard to the role of small molecules, recent research has revealed that small molecules produced by the gut microbiome are involved in cancer development. Small molecules can modulate antitumour immunity in the liver, and these molecules include lipopolysaccharide (LPS), bile acids (BAs), and lipoteichoic acid (LTA) [63-65]. Researchers have found that anaerobic species are involved in the production of butyrate, a short-chain fatty acid (SCFA) that can enhance the production of IL-10, restrain the activation of $\mathrm{NF}-\mathrm{KB}$, and eventually suppress the progression of colitis caused by cancer treatment [48, 66-68]. Moreover, research has proved that the microbiome plays a vital role in the metabolism of chemotherapeutic agents in Caenorhabditis elegans (C. elegans) $[69,70]$. Scott [70] found that the metabolism of bacterial RNA along with vitamins B6 and B9 can modulate the activation of prodrugs. A previous study also showed that inhibiting microbial $\beta$ glucuronidases could decrease the side effects induced by irinotecan, including severe diarrhoea caused by dysbiosis, which was related to chemotherapy in specific patients [49]. In brief, metabolism appears to be a necessary aspect of the mechanism by which the microbiome influences the efficacy and side effects of chemotherapy [7].

In regard to the mechanism by which the microbiome influences the efficacy and adverse reactions of immune checkpoint inhibitors, researchers have compared metabolic pathway enrichments and found changes in the metabolic functions of patients with metastatic melanoma receiving immune checkpoint inhibitors [20]. Gopalakrishnan found that anabolic functions predominated in responders to

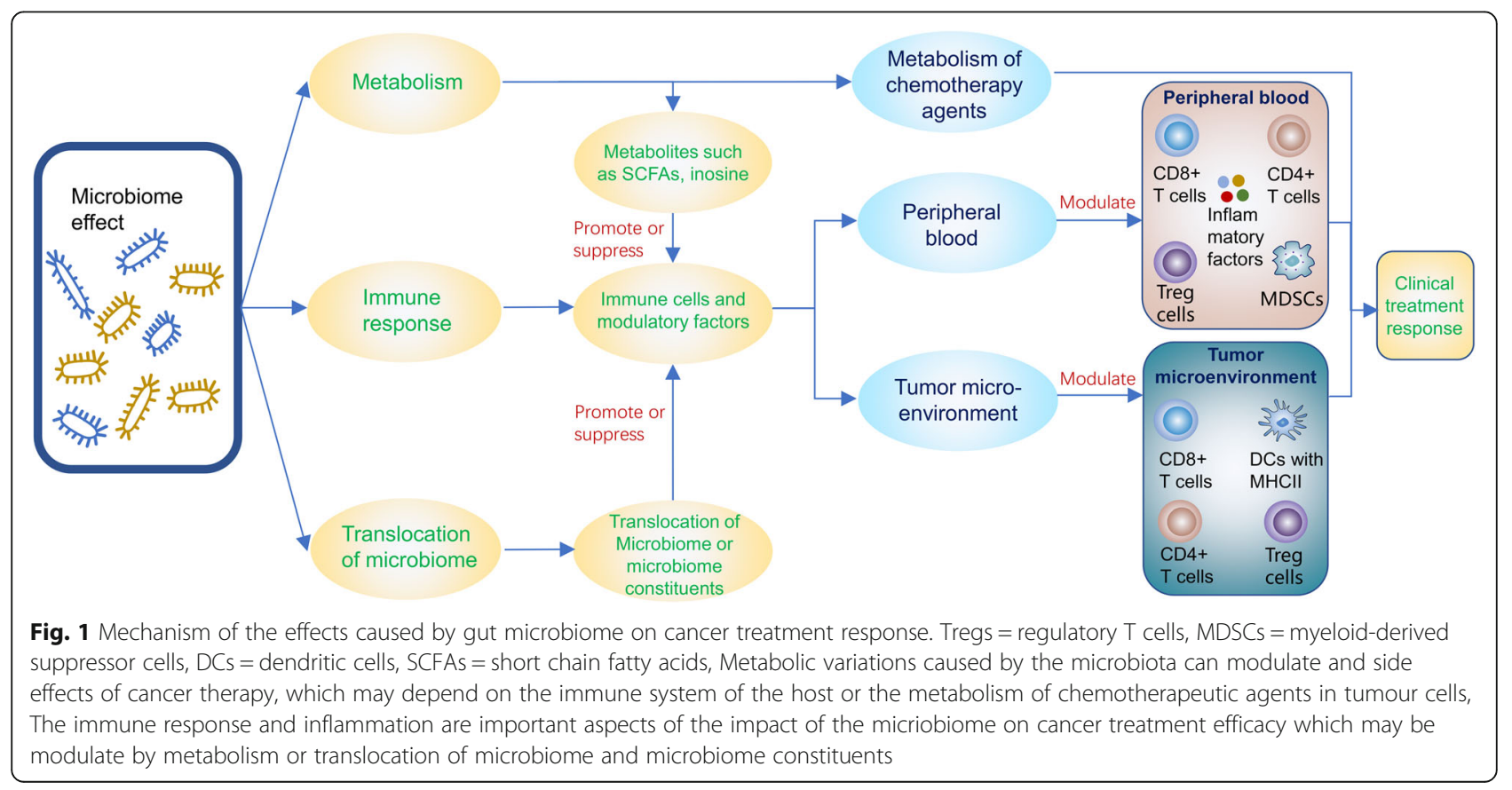


immune checkpoint inhibitors, including amino acid biosynthesis, which likely enhanced host immunity [71], whereas catabolic functions predominated in nonresponders. Recent research has shown that intestinal B. pseudolongum could amplify the response to immunotherapy by producing the metabolite inosine [42]. Additionally the decreased function of the gut barrier caused by immunotherapy enhanced the translocation of inosine, which has the ability to activate antitumour $\mathrm{T}$ cells.

In summary, metabolic variations caused by the microbiota can modulate the efficacy and side effects of cancer therapy, which may depend on the immune system of the host or the metabolism of chemotherapeutic agents in tumour cells.

\section{Immune response}

The influence of metabolic alterations on cancer therapy appears to be mostly dependent on the modulation of cancer immunity. Researchers have found that the FOLFOX chemotherapy regimen in a colorectal cancer model activated NF- $k B$, subsequently increasing the production of TNF and IL-6 and consequently leading to local inflammation and mucosal damage [50]. Moreover, the mechanism of the damage caused by radiotherapy may rely on the activation of IL-1B, while blocking IL$1 \mathrm{~B}$ or rebuilding the gut microbiome system can reduce this damage [55]. Recent research has revealed the relationship between small molecules such as LPS, BAs, and LTA produced by the gut microbiome and antitumour immunity in the liver, as previously reported [63-65]. The production of the metabolite inosine as a result of intestinal $B$. pseudolongum likely leads to the activation of antitumour $\mathrm{T}$ cells that express adenosine A2A receptor and enhance immunotherapy [42]. According to previous research, the gut microbiome can not only activate APCs and reinforce the mucosal barrier but can also promote IgA secretion and maintain the balance of Tregs and T-helper-17 (Th17) cells, which eventually promotes the balance of the cytokines that cause or inhibit inflammation [22, 24, 30, 41, 72-76].

In general, metabolism mostly depends on the modulation of cancer immunity to influence the effect of cancer therapy; thus, the immune response and inflammation are important aspects of the impact of the microbiome on cancer treatment efficacy and are worth further study.

\section{Translocation of the microbiota or microbiome constituents}

Previous research has proven that bacteria can pass through the barrier of the intestine and enter the secondary lymphoid organs to modulate the efficacy and toxicity of chemotherapy [23, 45]. Nevertheless, research on the translocation of microbiota showed that this phenomenon can be observed not only in lymphoid organs but also in other organs, including the pancreas. Riquelme performed faecal microbial transplantation (FMT) on a preclinical model of PDAC and examined the abundance of operational taxonomic units (OTUs) in patient donor samples, pre-FMT and post-FMT murine faecal samples, and murine tumours 5 weeks after tumour implantation to validate the association between the tumour microbiome and the gut microbiome [59]. He proved that the gut microbiome could regulate the composition of the tumour microbiome; thus, modification of the gut microbiome can lead to alterations in the tumour microbiome of PDAC patients by direct translocation of the gut microbiome into tumours. However, the dominant mechanism of the tumour microbiome alteration was its modulation by the different microbial landscapes and tumour microenvironments induced by the activation and infiltration of $\mathrm{CD} 8+\mathrm{T}$ cells into the tumours, which was related to the modulation of the gut microbiome [59]. The gut-lung microbiota axis is another clear avenue of cross-talk that is vital for modulating the host immune response [77]. The relationship between the gut microbiota and the lung microbiota may depend on metabolites produced by the gut microbiota, such as SCFAs, peptidoglycans or LPS, which are associated with the inflammatory response of the lung [78-80]. Researchers have also found that the interaction between the lung and gut microbiomes partially depends on direct microbiome translocation. The migration of immune cells from one site to the other or the release of bacteria-derived immunomodulatory molecules into the circulation system or the lymphatic system also play an important role in this interaction [81-83]. A report on the translocation of gut bacteria-derived products into the circulation revealed that this process could promote liver inflammation associated with liver disease progression and cancer risk $[84,85]$. However, the association between the prognosis of liver cancer patients and microbiome translocation has not yet been confirmed. The translocation of the microbiota and the relationship between the gut microbiome and locally resident microbiota or intratumour microbiota in other parts of the body are unclear and should be researched further in the future.

\section{Cancer therapy and locally resident microbiota or intratumour microbiota}

Locally resident microbiota and intratumour microbiota are a current research focus. Locally resident microbiota, especially the microbiota of the gastrointestinal tract and other parts of the digestive system, have been found to be closely related to the carcinogenesis of the resident organ [11, 27-29]. Previous studies have shown that susceptibility to oral squamous cell carcinoma (OSCC) [86], oesophageal cancer [87, 88], gastric cancer [89, 90], 
gastric diffuse large B cell lymphoma (DLBCL) [91], CRC (colorectal cancer) [92-94], gastric mucosaassociated lymphoid tissue lymphoma (MALT) [95], hepatocellular carcinoma (HCC) [96], pancreatic cancer [97], gallbladder cancer [98], lung cancer [99], breast cancer [100] and prostate cancer [101] is associated with locally resident microbiota. However, the relationship between locally resident microbiota and the efficacy therapy is still under investigation. For colorectal cancer (CRC) patients, the gut microbiome is also the locally resident microbiota at the tumour site. The subsequent discussion is divided into two sections, one concerning patients with CRC and another regarding patients with other cancers.

\section{Gut microbiome and CRC}

As mentioned previously, the gut microbiome can influence the therapeutic effects of immunotherapy, chemotherapy, radiation therapy and surgery for colorectal cancer along with influencing side effects. The influence of the intratumour microbiome of gastrointestinal cancer also plays an indispensable role in the outcome of cancer treatment. In a colon cancer model, Geller found that gemcitabine resistance was induced by intratumour bacteria in a murine model of colon cancer, which could be inhibited by combination treatment with antibiotics [102]. The mechanism may depend on the metabolism of gemcitabine caused by the intratumour microbiome. Intratumoral Gammaproteobacteria can influence gemcitabine metabolism and cause gemcitabine resistance. The value of the intratumour microbiome and the metabolism of tumour cells may be another target of future research on other cancers.

\section{Locally resident microbiomes and other cancers}

In PDAC, Riquelme found that the distinct species of the tumour microbiome from the long-term survivors of pancreatic cancer after tumour resection was a prognostic factor for survival, and the transplantation of longterm survivor gut microbiomes could restrict tumour growth by altering the tumour microbiome in murine models [59]. The author demonstrated that gut microbiota could modulate tumour microbiota and influence tumour growth. Researchers have also found that the removal of bacteria resident in pancreatic cancer was related to the immune response to PDAC, and altering the tumour microenvironment by inhibiting the infiltration of myeloid-derived suppressor cells (MDSCs) could enhance the differentiation of M1 macrophages, which stimulated the differentiation of Th1 cells and increased the number of activated CD4+ T cells and CD8+ T cells [7]. Interestingly, the removal of bacteria could even modulate the response of PDAC patients to ICIs by upregulating the expression of $\mathrm{PD}-1$. In regard to the specific mechanism of immune reprogramming, the microbiome of PDAC can differentially activate select Toll-like receptors of monocytic cells to generate a tolerogenic immune program inducing innate and adaptive immune suppression [7].

In prostate cancer patients, Banerjee [103] found distinct microbiome signatures of prostate cancer that were associated with the stages, grades and scores of prostate cancer by analyzing tumour tissue samples, revealing the value of analyzing locally resident flora for predicting the prognosis of prostate cancer patients.

In breast cancer, researchers have found enriched microbes by analyzing the microbiome of breast skin swabs and breast tissue from patients with breast cancer and healthy controls. The enriched microbes in the patients included Fusobacterium, Comamonadaceae, Atopobium, Gluconacetobacter, Bacteroidetes, Enterobacteriaceae, Hydrogenophaga, Staphylococcus and Bacillus [100, 104]. However, the association between the microbiome and cancer treatment is still under investigation.

In regard to the microbiome of the airway, a recent study compared brushing samples of bronchi from 24 lung cancer patients and 18 healthy controls. The samples collected from the patients included the unilateral lobar tumour and paired samples from the cancerous site and the opposite site of the tumour, i.e., the noncancerous site [105]. The author demonstrated that microbiota profile of the samples collected from the cancerous site of lung cancer patients was different from that of the samples collected from healthy controls, including the samples from the noncancerous site and from the healthy controls, which showed a lower microbial diversity than that of the noncancerous site and healthy controls. Tumour tissue had a higher abundance of Streptococcus and Neisseria than normal tissue, while Staphylococcus and Dialister were found to reside in normal tissue more frequently. There was a trend that the abundance of microbiota changed gradually from normal tissue to noncancerous site tissue to cancerous tissue in lung cancer patients, suggesting that the microbiota of the lung can clearly affect the tumour microenvironment, which is not restricted to the cancerous site but involves the whole lung and is likely related to cancer progression and patient prognosis [105]. The nasopharynx is the upper part of the pharynx, an indispensable part of the airway. The association between the nasopharynx microbiome and cancer treatment has not been well studied and meaningful results may be obtained in the future.

On the one hand, the intratumour microbiome is capable of decreasing the effective concentration of chemotherapeutic agents and the expression of major histocompatibility complex (MHC) class I as well as increasing the number of MDSCs. Also, the tumour microbiome can induce 
alternative immune checkpoints and restrict the clonal expansion of lymphocytes [72, 73]. On the other hand, the tumour microbiome can not only directly engage the innate immune system but can also produce more anti-inflammatory cytokines and increase the expression of targetable checkpoint molecules, which is likely to be beneficial to cancer immunity $[72,73]$. The influence of the tumour microbiome on the immune microenvironment is a double-edged sword and worthy of further study in a variety of cancers. In summary, the effect of locally resident microbiota or intratumour microbiota on cancer therapy has not been well studied. Although the function of some locally resident or intratumour bacteria has been confirmed in some individual cases, these studies mainly focused on the gut. In cancers of other areas of the digestive tract, there is not enough evidence for the interaction between the efficacy of cancer therapy and the locally resident microbiome. However, there is some evidence that locally resident microbiota are associated with local inflammation and the progression of cancer, indicating that patient prognosis could be improved through microbiome modification. In general, the bacteria resident in multiple areas of the human body seem to participate in the various stages of tumour development, the mechanism of which may rely on innate and specific immune responses and remains unknown.

\section{Discussion and prospective Our findings}

We discussed the potential role of gut microbiota and locally resident microbiota in cancer therapy and three major probable mechanisms underlying this relationship. We found that the influence of metabolism mostly depended on modulating cancer immunity to affect cancer therapy [48, 66-68], while some microbiota can directly modulate chemotherapeutic agent metabolism [102]. Microbiota translocation also depends on host metabolism and the immune system influence the efficacy of cancer immunity [78-83]. The efficacy of several cancer therapies, including radiation therapy, surgery, chemotherapy, and other kinds of therapy, such as cell transplant therapy, has been found to be associated with the gut microbiome or the locally resident microbiota or intratumour microbiota. The association between microbiota and cancer therapies tends to be influenced by the association between the therapies and the host immune response. In other words, if the response of the therapy is closely related to the immune response, the therapy tends to be greatly affected by the microbiome, especially the gut microbiome, which has been proven to be closely related to the host immunity of pathogens and cancer $[17,30,106]$. Cancer immunotherapy is dependent on host immunity and may be more likely to be affected by the microbiota. Immune checkpoint blockade beneficial for improving survival rates in many cancers and represents a breakthrough in cancer therapy [32]. The relationship between the efficacy of immune checkpoint blockade and the human microbiome has been confirmed for many malignancies [13, 14, 18-22, 41, 42]. Different tumours may have different "favourable microbiota", while the same kind of microbiota may have distinct effects on the same ICIs for different tumours. Instead of continuing research on the efficacy of specific microbiomes, research on the mechanisms and downstream pathways associated with immune response differences caused by microbiome differences may yield benefits.

\section{Methods to modulate the host microbiome}

The microbiome could be a beneficial target to improve cancer response to treatment. The major methods for modulating the microbiome to date include FMT [107-109], probiotics and prebiotics [3, 57, 108, 110], and diet control [111-113]. FMT-a therapy that has been used for inflammatory bowel disease [114], has been confirmed to improve the efficacy of cancer treatment $[20,59]$ in murine models and to extenuate ICI-associated colitis in clinical practice [107]. As shown by V. Gopalakrishnan [20], mice transplanted with stools from human responders with metastatic melanoma treated with ICIs showed improved responses to anti-PD-L1 therapy in contrast to the response of mice that were transplanted with stools from nonresponders. The median fold change in the tumour volume in mice transplanted with responder stools was 0.18 , while the median fold change of tumour volume in mice transplanted with nonresponders stools 1.52 $(\mathrm{P}<0.01)$, showing the promising efficacy of FMT. Routy [18] found that transplantation of Akkermansia Muciniphila(A. muciniphila) or A. muciniphila plus Enterococcus hirae(E. hirae) reversed the poor efficacy of PD1 blockade in germ-free mice treated by FMT with stools from human nonresponders. The tumour size of the $A$. muciniphila or A. muciniphila plus $E$. hirae-treated mice was much smaller than the tumour size of mice in the control group $(P=0.038$ in the A. muciniphila group and $\mathrm{P}<0.001$ in the $A$. muciniphila plus $E$. hirae group). Moreover, patients with ICI-associated colitis have been successfully treated with FMT [107]. Two patients with poor response to corticosteroids and anti-TNF- $\alpha$ agents were treated successfully by FMT, as confirmed by endoscopic evaluation and immunohistochemistry. FMT is becoming the most feasible way to modulate the gut microbiome. Transplantation of the entire ecosystem directly ensures the efficacy of the modulation. However, the complexity of the techniques, donor selection and persistence time should be considered. More clinical trials of faecal 
microbiota transplantation should be performed to address these problems. Probiotics have been used for the prevention of many diseases [115-118]. Although the simplicity of adjuvant therapy allows for long-term use, the objective efficacy of the therapy is difficult to assess and monitor; thus, more research is required to address these issues. The results of a recent randomized clinical trial showed that the combination of probiotics can significantly decrease the occurrence rate of high-grade OM caused by chemoradiotherapy compared to that observed in patients administered a placebo. The incidences of grade $0,1,2,3 \mathrm{OM}$ in the placebo group and the probiotic combination group were $0,0,54.29,45.71$ and $12.07 \%$, $55.17,17.24,15.52 \%(\mathrm{P}<0.0001)$, showing the feasibility of modulating the efficacy or side effects of cancer treatment by probiotics [57]. In regard to therapy dependent on the diet, although some reports show that specific diets are associated with carcinogenesis or the efficacy of cancer treatment [113, 119-121], no prospective trial has identified the specific relationship between treatment and diet. Moreover, patients may not adjust well to the new diet, reducing compliance. Diet modulation is likely to be used as a supplement to therapy in the future.

\section{Direction of future research}

The influence of the microbiome on the efficacy of treatment and the relationship between the host microbiome and cancer treatments efficacies should be explored in the future, especially in the context of immune checkpoint blockade. Mechanistic studies will likely identify targets for cancer therapy and allow for the modulation of the efficacy of cancer therapy directly without modulating the microbiome.

Research on the interaction between the immune response and microbiome should be further conducted on more cancer types to uncover the mechanism of the immune response, which may be modulated without altering the microbiome in the future. Modulating inflammation or the immune response by modulating inflammatory factors may be a better way to enhance cancer treatment efficacy, inspired by the effects of the microbiome.

Specific metabolites, such as inosine, can modulate the efficacy of cancer treatment, and this effect is not dependent on the microbiome. The metabolite inosine produced by the microbiome has been shown to modulate the efficacy of cancer therapy without modulating the microbiome in murine models [42], which may be used as an adjuvant agent for various kinds of cancer therapy in the future. The application of specific metabolites produced by the microbiome may replace the role of the microbiome. The efficacy should be studied further in more kinds of cancer and in clinical trials. Future research on the detailed mechanism of the effects caused by inosine or other metabolites should be performed as well, which may depend on research on the interaction between the immune response and microbiome-derived metabolites.

In addition to mechanistic research on metabolism and the immune response, finding a way to modulate the translocation of microbiota and microbiota-derived metabolites may be another future research direction to investigate the relationship between gut microbiota and locally resident microbiota or intratumour microbiota, which may be another important mechanism of the effects caused by the gut microbiome on cancer treatment.

Mechanistic studies of the influence of the locally resident microbiome on the tumour microenvironment should be performed by studying the interaction between the immune response and metabolism. Performing research on the modulation of locally resident microbiome may be a simple way to enhance the cancer treatment efficacy up to now.

\section{Conclusion}

We found that the microbiome can modulate the efficacy of cancer therapy by modulating metabolism to enhance or suppress the immune response to the tumour or by modulating the metabolism of antitumour agents. Some microbiomes can modulate the immune response directly, and the specific downstream pathway remains unknown. Future studies may concentrate on identifying unknown pathways, developing a feasible plan for the modulation of the gut microbiome and identifying the mechanism of modulation to identify treatment targets. The interaction between the host immune response and the microbiome should be further studied to identify the specific pathway involved in the activation of immune cells caused by the human microbiome. In addition, the mechanism of the effects induced by the human microbiome in the various stages of tumour development, such as carcinogenesis and metastasis, has not yet been well studied and the interaction between the microbiome, metabolism, immune response and translocation of the microbiome should be further studied in future. Future research on the relationship between host immunity and the host microbiome will create a brighter future cancer patients.

\footnotetext{
Abbreviations

ICl: Immune checkpoint inhibitors; PD-1: Programmed death receptor; PDL1: Programmed death receptor ligand; CTLA-4: cytotoxic T lymphocyteassociated protein 4; MM: Metastatic melanomas; NSCLC: Non-small-cell lung cancer; UC: Urothelial carcinoma; RCC: Renal cell carcinoma;

CTX: Cyclophosphamide; pTh17: "pathogenic" Thelper 17; Th1: T helper cells; CTL: Cytotoxic T cells; ROS: Reactive oxygen species; FOLFOX: 5-FU, Leucovorin Calcium and oxaliplatin; NF-KB: Nuclear transcription factor-kB; TNF: Tumour necrosis factor; IL-6: Interleukin-6; CRT: Cisplatin and radiation therapy; CSCC: Cervical squamous cell carcinoma; IL-1B: Interleukin-1B; OM: Oral mucositis; PDAC: Pancreatic adenocarcinoma;
} 
HSCT: Haematopoietic stem cell transplant; GVHD: Graft versus-host disease; ACT: Adoptive T cell therapy; DCs: Dendritic cells; IL12: Interleukin-12; ATT: Axis-targeted therapy; OSCC: Oral squamous cell carcinoma; DLBCL: Diffuse large B cell lymphoma; CRC: Colorectal cancer; MALT: Mucosa-associated lymphoid tissue; HCC: Hepatocellular carcinoma; LPS: Lipopolysaccharide; BAs: Bile acids; LTA: Lipoteichoic acid; SCFA: Shortchain fatty acid; MDSC: Myeloid-derived suppressor cells; APC: Antigen presenting cells; MHC: Major histocompatibility complex; FMT: Faecal microbial transplantation; OTU: Operational taxonomic unit; PFS: Progressionfree survival; OS: Overall survival; ATB: Antibiotics; C. elegans: Caenorhabditis elegans; A. muciniphila: Akkermansia Muciniphila; E. hirae: Enterococcus hirae

\section{Acknowledgements}

Not applicable.

\section{Authors' contributions}

ZKY and RY search and summarized the research. YPL and XYC were responsible for the selection of literature. ZKY and RLX were responsible for drafting the manuscript. MYC and PYH put forward the concepts of the study. All the authors revised the manuscript. All the authors approved the final manuscript.

\section{Funding}

Funding was provided by the Program of Sun Yat-Sen University for Clinica Research 5010 Program (No.201310, No.2018015, No.2018029), the National Natural Science Foundation of China (No.81772895, No.81874134), the KeyArea Research and Development of Guangdong Province (No.2020B1111190001), Guangdong Province Science and Technology Development Special Funds (Frontier and Key Technology Innovation Direction Major Science and Technology Project) (No.2017B020226004), CSCO-JunShi Cancer Immunotherapy Clinical Research Fund (No.Y-JS2019-002).

\section{Availability of data and materials} Not applicable.

\section{Declarations}

Ethics approval and consent to participate

Not applicable.

\section{Consent for publication}

Not applicable.

\section{Competing interests}

The authors declare that they have no conflicts of interest.

\section{Author details}

'Department of Nasopharyngeal Carcinoma, Sun Yat-sen University Cancer Center, 651 Dongfeng East Road, Guangzhou 510060, People's Republic of China. ${ }^{2}$ Sun Yat-sen University Cancer Center; State Key Laboratory of Oncology in South China; Collaborative Innovation Center for Cancer Medicine, Guangdong Key Laboratory of Nasopharyngeal Carcinoma Diagnosis and Therapy, Guangzhou 510060, China.

Received: 27 November 2020 Accepted: 4 August 2021

\section{Published online: 19 August 2021}

\section{References}

1. Institute of Medicine Food F. The National Academies Collection: Reports funded by National Institutes of Health. In: The Human Microbiome, Diet, and Health: Workshop Summary. Washington (DC): National Academies Press (US). Copyright (c) 2013, National Academy of Sciences; 2013.

2. Hill C, Guarner F, Reid G, Gibson GR, Merenstein DJ, Pot B, et al. The international scientific Association for Probiotics and Prebiotics consensus statement on the scope and appropriate use of the term probiotic. Nat Rev Gastroenterol Hepatol. 2014;11(8):506-14. https://doi.org/10.1038/nrgastro.2 014.66.

3. Yoo JY, Kim SS. Probiotics and prebiotics: present status and future perspectives on metabolic disorders. Nutrients. 2016;8(3):173.
4. Lynch SV, Pedersen O. The human intestinal microbiome in health and disease. N Engl J Med. 2016;375(24):2369-79. https://doi.org/10.1056/ NEJMra1600266

5. Cho I, Blaser MJ. The human microbiome: at the interface of health and disease. Nat Rev Genet. 2012;13(4):260-70. https://doi.org/10.1038/nrg3182.

6. Torre LA, Siegel RL, Ward EM, Jemal A. Global Cancer incidence and mortality rates and trends--an update. Cancer Epidemiol Biomark Prev. 2016; 25(1):16-27. https://doi.org/10.1158/1055-9965.EPI-15-0578.

7. Pushalkar S, Hundeyin M, Daley D, Zambirinis CP, Kurz E, Mishra A, et al. The pancreatic Cancer microbiome promotes oncogenesis by induction of innate and adaptive immune suppression. Cancer Discov. 2018;8(4):403-16. https://doi.org/10.1158/2159-8290.CD-17-1134

8. Mima K, Sukawa Y, Nishihara R, Qian ZR, Yamauchi M, Inamura K, et al. Fusobacterium nucleatum and T cells in colorectal carcinoma. JAMA Oncol. 2015:1(5):653-61.

9. Rubinstein MR, Wang X, Liu W, Hao Y, Cai G, Han YW. Fusobacterium nucleatum promotes colorectal carcinogenesis by modulating E-cadherin/ beta-catenin signaling via its FadA Adhesin. Cell Host Microbe. 2013;14(2): 195-206.

10. Moore PS, Chang Y. Why do viruses cause cancer? Highlights of the first century of human tumour virology. Nat Rev Cancer. 2010;10(12):878-89.

11. Wheeler KM, Liss MA. The microbiome and prostate cancer risk. Curr Urol Rep. 2019:20(10).

12. Kumar S, Metz DC, Ellenberg S, Kaplan DE, Goldberg DS. Risk factors and incidence of gastric cancer after detection of Helicobacter pylori infection: a large cohort study. Gastroenterology. 2020;158(3):527-536.e527.

13. Chaput N, Lepage P, Coutzac C, Soularue E, Le Roux K, Monot C, et al. Baseline gut microbiota predicts clinical response and colitis in metastatic melanoma patients treated with ipilimumab. Ann Oncol. 2017:28(6):1368-79.

14. Dubin K, Callahan MK, Ren B, Khanin R, Viale A, Ling L, et al. Intestinal microbiome analyses identify melanoma patients at risk for checkpointblockade-induced colitis. Nat Commun. 2016;7(1). https://doi.org/10.1038/ ncomms10391.

15. Jeng RR, Taur Y, Devlin SM, Ponce DM, Goldberg JD, Ahr KF, et al. Intestinal Blautia is associated with reduced death from graft-versus-host disease. Biol Blood Marrow Transplant. 2015;21(8):1373-83.

16. Taur $Y$, Jeng RR, Perales M-A, Littmann ER, Morjaria S, Ling L, et al. The effects of intestinal tract bacterial diversity on mortality following allogeneic hematopoietic stem cell transplantation. Blood. 2014;124(7):1174-82.

17. Peterson SN, Bradley LM, Ronai ZA. The gut microbiome: an unexpected player in cancer immunity. Curr Opin Neurobiol. 2020;62:48-52. https://doi. org/10.1016/j.conb.2019.09.016.

18. Routy B, Le Chatelier E, Derosa L, Duong CPM, Alou MT, Daillere R, et al. Gut microbiome influences efficacy of PD-1-based immunotherapy against epithelial tumors. Science. 2018;359(6371):91.

19. Matson V, Fessler J, Bao R, Chongsuwat T, Zha Y, Alegre M-L, et al. The commensal microbiome is associated with anti-PD-1 efficacy in metastatic melanoma patients. Science. 2018;359(6371):104

20. Gopalakrishnan V, Spencer CN, Nezi L, Reuben A, Andrews MC, Karpinets TV, et al. Gut microbiome modulates response to anti-PD-1 immunotherapy in melanoma patients. Science. 2018;359(6371):97-103.

21. Frankel $A E$, Coughlin LA, Kim J, Froehlich TW, Xie Y, Frenkel EP, et al, Metagenomic shotgun sequencing and unbiased Metabolomic profiling identify specific human gut microbiota and metabolites associated with immune checkpoint therapy efficacy in melanoma patients. Neoplasia. 2017; 19(10):848-55

22. Sivan A, Corrales L, Hubert N, Williams JB, Aquino-Michaels K, Earley ZM, et al. Commensal Bifidobacterium promotes antitumor immunity and facilitates anti-PD-L1 efficacy. Science. 2015;350(6264):1084-9.

23. Viaud S, Saccheri F, Mignot G, Yamazaki T, Daillere R, Hannani D, et al. The intestinal microbiota modulates the anticancer immune effects of cyclophosphamide. Science. 2013;342(6161):971-6. https://doi.org/10.1126/ science.1240537.

24. lida N, Dzutsev A, Stewart CA, Smith L, Bouladoux N, Weingarten RA, et al. Commensal Bacteria control Cancer response to therapy by modulating the tumor microenvironment. Science. 2013;342(6161):967-70. https://doi.org/1 $0.1126 /$ science 1240527.

25. Sun J-Y, Yin T-L, Zhou J, Xu J, Lu X-J. Gut microbiome and cancer immunotherapy. J Cell Physiol. 2020;235(5):4082-8. https://doi.org/10.1002/ jcp.29359. 
26. Zitvogel L, Ma Y, Raoult D, Kroemer G, Gajewski TF. The microbiome in cancer immunotherapy: diagnostic tools and therapeutic strategies. Science. 2018;359(6382):1366-70.

27. Chunxi L, Haiyue L, Yanxia L, Jianbing $P$, Jin $S$. The gut microbiota and respiratory diseases: new evidence. J Immunol Res. 2020;2020.

28. Elsalem L, Jum'ah AA, Alfagih MA, Aloudat $O$. The bacterial microbiota of gastrointestinal cancers: role in Cancer pathogenesis and therapeutic perspectives. Clin Exp Gastroenterol. 2020;13:151-85.

29. Chen J, Douglass J, Prasath V, Neace M, Atrchian S, Manjili MH, et al. The microbiome and breast cancer: a review. Breast Cancer Res Treat. 2019; 178(3):493-6. https://doi.org/10.1007/s10549-019-05407-5.

30. Gopalakrishnan V, Helmink BA, Spencer CN, Reuben A, Wargo JA. The influence of the gut microbiome on Cancer, immunity, and Cancer immunotherapy. Cancer Cell. 2018;33(4):570-80.

31. Pitt JM, Vétizou M, Waldschmitt N, Kroemer G, Chamaillard M, Boneca IG et al. Fine-tuning Cancer immunotherapy: optimizing the gut microbiome. Cancer Res. 2016;76(16):4602-7.

32. Pardoll D. Cancer and the immune system: basic concepts and targets for intervention. Semin Oncol. 2015:42(4):523-38.

33. Fang $W$, Yang $Y$, Ma $Y$, Hong $S$, Lin L, He X, et al. Camrelizumab (SHR1210) alone or in combination with gemcitabine plus cisplatin for nasopharyngeal carcinoma: results from two single-arm, phase 1 trials. Lancet Oncol. 2018;19(10):1338-50. https://doi.org/10.1016/S1470-2045(1 8)30495-9.

34. Ribas A, Hamid O, Daud A, Hodi FS, Wolchok JD, Kefford R, et al. Association of Pembrolizumab with Tumor Response and Survival among Patients with Advanced Melanoma. JAMA. 2016;315(15):1600-9.

35. Motzer RJ, Escudier B, McDermott DF, George S, Hammers HJ, Srinivas S, et al. Nivolumab versus Everolimus in advanced renal-cell carcinoma. N Engl J Med. 2015;373(19):1803-13. https://doi.org/10.1056/NEJMoa1510665.

36. Borghaei H, Paz-Ares L, Horn L, Spigel DR, Steins M, Ready NE, et al. Nivolumab versus docetaxel in advanced nonsquamous non-small-cell lung Cancer. N Engl J Med. 2015;373(17):1627-39. https://doi.org/10.1056/ NEJMoa1507643.

37. Ansell SM, Lesokhin AM, Borrello I, Halwani A, Scott EC, Gutierrez M, et al. PD-1 blockade with Nivolumab in relapsed or refractory Hodgkin's lymphoma. N Engl J Med. 2015;372(4):311-9.

38. Robert C, Thomas L, Bondarenko I, O'Day S, Weber J, Garbe C, et al. Ipilimumab plus Dacarbazine for previously untreated metastatic melanoma. N Engl J Med. 2011;364(26):2517-26.

39. Hodi FS, O'Day SJ, McDermott DF, Weber RW, Sosman JA, Haanen JB, et al. Improved survival with Ipilimumab in patients with metastatic melanoma. N Engl J Med. 2010;363(8):711-23.

40. Barrueto L, Caminero F, Cash L, Makris C, Lamichhane P, Deshmukh RR. Resistance to checkpoint inhibition in Cancer immunotherapy. Transl Oncol. 2020;13(3):100738. https://doi.org/10.1016/j.tranon.2019.12.010.

41. Vetizou M, Pitt JM, Daillere R, Lepage P, Waldschmitt N, Flament C, et al. Anticancer immunotherapy by CTLA-4 blockade relies on the gut microbiota. Science. 2015;350(6264):1079.

42. Mager LF, Burkhard R, Pett N, Cooke NCA, Brown K, Ramay H, et al. Microbiome-derived inosine modulates response to checkpoint inhibitor immunotherapy. Science. 2020;369(6510):1481

43. Pinato DJ, Howlett S, Ottaviani D, Urus H, Patel A, Mineo T, et al. Association of Prior Antibiotic Treatment with Survival and Response to immune checkpoint inhibitor therapy in patients with Cancer. JAMA Oncol. 2019; 5(12):1774-8. https://doi.org/10.1001/jamaoncol.2019.2785.

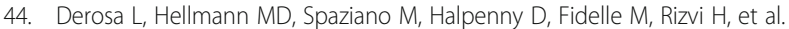
Negative association of antibiotics on clinical activity of immune checkpoint inhibitors in patients with advanced renal cell and non-small-cell lung cancer. Ann Oncol. 2018;29(6):1437-44.

45. Daillere R, Vetizou M, Waldschmitt N, Yamazaki T, Isnard C, Poirier-Colame V, et al. Enterococcus hirae and Barnesiella intestinihominis facilitate cyclophosphamide-induced therapeutic immunomodulatory effects Immunity. 2016;45(4):931-43. https://doi.org/10.1016/j.immuni.2016.09.009.

46. Sistigu A, Viaud S, Chaput N, Bracci L, Proietti E, Zitvogel L. Immunomodulatory effects of cyclophosphamide and implementations for vaccine design. Semin Immunopathol. 2011;33(4):369-83. https://doi.org/1 0.1007/s00281-011-0245-0.

47. Yu T, Guo F, Yu Y, Sun T, Ma D, Han J, Qian Y, Kryczek I, Sun D, Nagarsheth $\mathrm{N}$ et al Fusobacterium nucleatum promotes chemoresistance to colorectal cancer by modulating autophagy. Cell 2017, 170(3):548
48. Pouncey AL, Scott AJ, Alexander JL, Marchesi J, Kinross J. Gut microbiota, chemotherapy and the host: the influence of the gut microbiota on cancer treatment. Ecancermedicalscience. 2018;12:868.

49. Guthrie L, Gupta S, Daily J, Kelly L. Human microbiome signatures of differential colorectal cancer drug metabolism. NPJ Biofilms Microbiomes. 2017;3(1):27. https://doi.org/10.1038/s41522-017-0034-1.

50. Chang CW, Liu CY, Lee HC, Huang YH, Li LH, Chiau JC, et al. Lactobacillus casei variety rhamnosus probiotic preventively attenuates 5-fluorouracil/ Oxaliplatin-induced intestinal injury in a syngeneic colorectal Cancer model. Front Microbiol. 2018;9:983. https://doi.org/10.3389/fmicb.2018.00983.

51. Colbert LE, Previs R, Medrano AYD, Eifel PJ, Jhingran A, Ramondetta L, et al. Rectal microbiome diversity predicts disease response at completion of radiation therapy for squamous cell carcinoma of the cervix. Int J Radiat Oncol Biol Phys. 2017;99(2):S51. https://doi.org/10.1016/j.jjrobp.2017.06.129.

52. Barker HE, Paget JT, Khan AA, Harrington KJ. The tumour microenvironment after radiotherapy: mechanisms of resistance and recurrence. Nat Rev Cancer. 2015;15(7):409-25.

53. Wang A, Ling Z, Yang Z, Kiela PR, Wang T, Wang C, et al. Gut microbial dysbiosis may predict diarrhea and fatigue in patients undergoing pelvic cancer radiotherapy: a pilot study. PLoS One. 2015;10(5):e0126312.

54. Touchefeu Y, Montassier E, Nieman K, Gastinne T, Potel G, Bruley des Varannes $S$, et al. Systematic review: the role of the gut microbiota in chemotherapy- or radiation-induced gastrointestinal mucositis - current evidence and potential clinical applications. Aliment Pharmacol Ther. 2014; 40(5):409-21.

55. Gerassy-Vainberg S, Blatt A, Danin-Poleg Y, Gershovich K, Sabo E, Nevelsky $A$, et al. Radiation induces proinflammatory dysbiosis: transmission of inflammatory susceptibility by host cytokine induction. Gut. 2018;67(1):97107. https://doi.org/10.1136/gutjnl-2017-313789.

56. Guo H, Chou WC, Lai Y, Liang K, Tam JW, Brickey WJ, et al. Multi-omics analyses of radiation survivors identify radioprotective microbes and metabolites. Science. 2020;370(6516).

57. Jiang C, Wang H, Xia C, Dong Q, Chen E, Qiu Y, et al. A randomized, double-blind, placebo-controlled trial of probiotics to reduce the severity of oral mucositis induced by chemoradiotherapy for patients with nasopharyngeal carcinoma. Cancer. 2019;125(7):1081-90.

58. Bartolini I, Risaliti M, Ringressi MN, Melli F, Nannini G, Amedei A, et al. Role of gut microbiota-immunity axis in patients undergoing surgery for colorectal cancer: Focus on short and long-term outcomes. World J Gastroenterol. 2020;26(20).

59. Riquelme E, Zhang Y, Zhang L, Montiel M, Zoltan M, Dong W, et al. Tumor microbiome diversity and composition influence pancreatic Cancer outcomes. Cell. 2019;178(4):795-806 e712. https://doi.org/10.1016/j.cell.2019. 07.008 .

60. Peled JU, Devlin SM, Staffas A, Lumish M, Khanin R, Littmann ER, et al. Intestinal microbiota and relapse after hematopoietic-cell transplantation. J Clin Oncol. 2017;35(15):1650-9.

61. Uribe-Herranz M, Bittinger K, Rafail S, Guedan S, Pierini S, Tanes C, et al. Gut microbiota modulates adoptive cell therapy via CD8a dendritic cells and IL12. JCl Insight. 2018;3(4).

62. Sfanos KS, Markowski MC, Peiffer LB, Ernst SE, White JR, Pienta KJ, et al. Compositional differences in gastrointestinal microbiota in prostate cancer patients treated with androgen axis-targeted therapies. Prostate Cancer Prostatic Dis. 2018;21(4):539-48. https://doi.org/10.1038/s41391-018-0061-X.

63. Ma C, Han M, Heinrich B, Fu Q, Zhang Q, Sandhu M, et al. Gut microbiomemediated bile acid metabolism regulates liver cancer via NKT cells. Science. 2018;360(6391).

64. Loo TM, Kamachi F, Watanabe $Y$, Yoshimoto S, Kanda H, Arai Y, et al. Gut microbiota promotes obesity-associated liver Cancer through PGE (2)-mediated suppression of antitumor immunity. Cancer Discov. 2017; 7(5):522-38.

65. Singh V, Yeoh BS, Chassaing B, Xiao X, Saha P, Aguilera Olvera R, et al. Dysregulated Microbial Fermentation of Soluble Fiber Induces Cholestatic Liver Cancer. Cell. 2018:175(3):679-694.e622

66. Dos Reis SA, da Conceição LL, Siqueira NP, Rosa DD, da Silva LL, Peluzio MD. Review of the mechanisms of probiotic actions in the prevention of colorectal cancer. Nutr Res. 2017;37:1-19. https://doi.org/10.1016/j.nutres.201 6.11 .009 .

67. Serban DE. Gastrointestinal cancers: influence of gut microbiota, probiotics and prebiotics. Cancer Lett. 2014;345(2):258-70. https://doi.org/10.1016/j.ca nlet.2013.08.013 
68. Sun M, Wu W, Chen L, Yang W, Huang X, Ma C, et al. Microbiota-derived short-chain fatty acids promote Th1 cell IL-10 production to maintain intestinal homeostasis. Nat Commun. 2018;9(1):3555. https://doi.org/10.103 8/s41467-018-05901-2.

69. García-González AP, Ritter AD, Shrestha S, Andersen EC, Yilmaz LS, Walhout AJM. Bacterial Metabolism Affects the C. elegans Response to Cancer Chemotherapeutics. Cell. 2017;169(3):431-441.e438.

70. Scott TA, Quintaneiro LM, Norvaisas P, Lui PP, Wilson MP, Leung KY, et al. Host-microbe co-metabolism dictates cancer drug efficacy in C. elegans. Cell. 2017;169(3):442-456.e418.

71. Blacher E, Levy M, Tatirovsky E, Elinav E. Microbiome-modulated metabolites at the Interface of host immunity. J Immunol. 2017;198(2):572-80. https:// doi.org/10.4049/jimmunol.1601247.

72. Cogdill AP, Gaudreau PO, Arora R, Gopalakrishnan V, Wargo JA. The impact of Intratumoral and gastrointestinal microbiota on systemic Cancer therapy. Trends Immunol. 2018;39(11):900-20.

73. Zitvogel L, Daillère R, Roberti MP, Routy B, Kroemer G. Anticancer effects of the microbiome and its products. Nat Rev Microbiol. 2017;15(8):465-78. https://doi.org/10.1038/nrmicro.2017.44.

74. Honda K, Littman DR. The microbiota in adaptive immune homeostasis and disease. Nature. 2016;535(7610):75-84. https://doi.org/10.1038/nature18848.

75. Round JL, Mazmanian SK. Inducible Foxp3+ regulatory T-cell development by a commensal bacterium of the intestinal microbiota. Proc Natl Acad Sci U S A. 2010;107(27):12204-9.

76. Levy M, Kolodziejczyk AA, Thaiss CA, Elinav E. Dysbiosis and the immune system. Nat Rev Immunol. 2017;17(4):219-32. https://doi.org/10.1038/nri.2017.7.

77. Dang AT, Marsland BJ. Microbes, metabolites, and the gut-lung axis. Mucosal Immunol. 2019;12(4):843-50. https://doi.org/10.1038/s41385-0190160-6.

78. Ichinohe T, Pang IK, Kumamoto Y, Peaper DR, Ho JH, Murray TS, et al. Microbiota regulates immune defense against respiratory tract influenza a virus infection. Proc Natl Acad Sci U S A. 2011;108(13):5354-9.

79. Kalliomäki M, Kirjavainen P, Eerola E, Kero P, Salminen S, Isolauri E. Distinct patterns of neonatal gut microflora in infants in whom atopy was and was not developing. J Allergy Clin Immunol. 2001;107(1):129-34.

80. Wypych TP, Wickramasinghe LC, Marsland BJ. The influence of the microbiome on respiratory health. Nat Immunol. 2019;20(10):1279-90. https://doi.org/10.1038/s41590-019-0451-9.

81. Fabbrizzi A, Amedei A, Lavorini F, Renda T, Fontana G. The lung microbiome: clinical and therapeutic implications. Intern Emerg Med. 2019; 14(8):1241-50. https://doi.org/10.1007/s11739-019-02208-y.

82. Carbone C, Piro G, Di Noia V, D'Argento E, Vita E, Ferrara MG, et al. Lung and gut microbiota as potential hidden driver of immunotherapy efficacy in lung cancer. Mediat Inflamm. 2019;2019.

83. McGhee JR, Fujihashi K. Inside the mucosal immune system. PLoS Biol. 2012; 10(9):e1001397. https://doi.org/10.1371/journal.pbio.1001397.

84. Yang B, Petrick JL, Thistle JE, Pinto LA, Kemp TJ, Hao Quang T, et al. Bacterial translocation and risk of liver Cancer in a Finnish cohort. Cancer Epidemiol Biomark Prev. 2019;28(4):807-13.

85. Chen D, Le TH, Shahidipour H, Read SA, Ahlenstiel G. The role of gutderived microbial antigens on liver fibrosis initiation and progression. Cells. 2019;8(11).

86. Katz J, Onate MD, Pauley KM, Bhattacharyya I, Cha S. Presence of Porphyromonas gingivalis in gingival squamous cell carcinoma. Int J Oral Sci. 2011;3(4):209-15. https://doi.org/10.4248/IJOS11075.

87. Zaidi AH, Kelly LA, Kreft RE, Barlek M, Omstead AN, Matsui D, et al. Associations of microbiota and toll-like receptor signaling pathway in esophageal adenocarcinoma. BMC Cancer. 2016;16(1):52. https://doi.org/1 0.1186/s12885-016-2093-8

88. Nasrollahzadeh D, Malekzadeh R, Ploner A, Shakeri R, Sotoudeh M, Fahimi S, et al. Variations of gastric corpus microbiota are associated with early esophageal squamous cell carcinoma and squamous dysplasia. Sci Rep. 2015;5.

89. Bartchewsky W Jr, Martini MR, Masiero M, Squassoni AC, Alvarez MC, Ladeira MS, et al. Effect of helicobacter pylori infection on IL-8, IL-1 and COX-2 expression in patients with chronic gastritis and gastric cancer. Scand J Gastroenterol. 2009;44(2):153-61. https://doi.org/10.1080/003 65520802530853.

90. Maeda M, Moro H, Ushijima T. Mechanisms for the induction of gastric cancer by helicobacter pylori infection: aberrant DNA methylation pathway. Gastric Cancer. 2017;20:S8-S15.
91. Kuo S-H, Chen L-T, Lin C-W, Yeh K-H, Shun C-T, Tzeng Y-S, et al. Expressions of the CagA protein and CagA-signaling molecules predict helicobacter pylori dependence of early-stage gastric DLBCL. Blood. 2017;129(2):188-98.

92. Abdulamir AS, Hafidh RR, Abu Bakar F. The association of Streptococcus bovis/gallolyticus with colorectal tumors: the nature and the underlying mechanisms of its etiological role. J Exp Clin Cancer Res. 2011;30.

93. Shah MS, DeSantis T, Yamal J-M, Weir T, Ryan EP, Cope JL, et al. Repurposing 165 rRNA gene sequence data from within case paired tumor biopsy and tumor-adjacent biopsy or fecal samples to identify microbial markers for colorectal cancer. PLoS One. 2018;13(11).

94. Abdulamir AS, Hafidh RR, Abu Bakar F. Molecular detection, quantification, and isolation of Streptococcus gallolyticus bacteria colonizing colorectal tumors: inflammation-driven potential of carcinogenesis via IL-1, COX-2, and IL-8. Mol Cancer. 2010;9.

95. Kuo SH, Wu MS, Yeh KH, Lin CW, Hsu PN, Chen LT, et al. Novel insights of lymphomagenesis of Helicobacter pylori-dependent gastric mucosaassociated lymphoid tissue lymphoma. Cancers. 2019;11(4).

96. Huang Y, Fan XG, Wang ZM, Zhou JH, Tian XF, Li N. Identification of helicobacter species in human liver samples from patients with primary hepatocellular carcinoma. J Clin Pathol. 2004;57(12):1273-7.

97. Karpiński TM. The microbiota and pancreatic Cancer. Gastroenterol Clin N Am. 2019;48(3):447-64. https://doi.org/10.1016/j.gtc.2019.04.008.

98. Nath G, Gulati AK, Shukla VK. Role of bacteria in carcinogenesis, with special reference to carcinoma of the gallbladder. World J Gastroenterol. 2010; 16(43):5395-404. https://doi.org/10.3748/wjg.v16.i43.5395.

99. Lee SH, Sung JY, Yong D, Chun J, Kim SY, Song JH, et al. Characterization of microbiome in bronchoalveolar lavage fluid of patients with lung cancer comparing with benign mass like lesions. Lung Cancer. 2016;102:89-95. https://doi.org/10.1016/j.lungcan.2016.10.016.

100. Hieken TJ, Chen J, Hoskin TL, Walther-Antonio M, Johnson S, Ramaker S, et al. The microbiome of aseptically collected human breast tissue in benign and malignant disease. Sci Rep. 2016;6(1):30751. https://doi.org/10.1 038/srep30751.

101. Namiki K, Goodison S, Porvasnik S, Allan RW, Iczkowski KA, Urbanek C, et al. Persistent exposure to Mycoplasma induces malignant transformation of human prostate cells. PLoS One. 2009;4(9):e6872.

102. Geller LT, Barzily-Rokni M, Danino T, Jonas OH, Shental N, Nejman D, et al. Potential role of intratumor bacteria in mediating tumor resistance to the chemotherapeutic drug gemcitabine. Science. 2017;357(6356):1156-60. https://doi.org/10.1126/science.aah5043.

103. Banerjee S, Alwine JC, Wei Z, Tian T, Shih N, Sperling C, et al. Microbiome signatures in prostate cancer. Carcinogenesis. 2019;40(6):749-64.

104. Urbaniak C, Gloor GB, Brackstone M, Scott L, Tangney M, Reid G. The microbiota of breast tissue and its association with breast Cancer. Appl Environ Microbiol. 2016;82(16):5039-48. https://doi.org/10.1128/AEM.01235-16.

105. Liu HX, Tao LL, Zhang J, Zhu YG, Zheng Y, Liu D, et al. Difference of lower airway microbiome in bilateral protected specimen brush between lung cancer patients with unilateral lobar masses and control subjects. Int J Cancer. 2018;142(4):769-78. https://doi.org/10.1002/ijc.31098.

106. Rooks MG, Garrett WS. Gut microbiota, metabolites and host immunity. Nat Rev Immunol. 2016;16(6):341-52.

107. Wang Y, Wiesnoski DH, Helmink BA, Gopalakrishnan V, Choi K, DuPont HL, et al. Fecal microbiota transplantation for refractory immune checkpoint inhibitor-associated colitis. Nat Med. 2018;24(12):1804.

108. Suez J, Zmora N, Zilberman-Schapira G, Mor U, Dori-Bachash M, Bashiardes $\mathrm{S}$, et al. Post-antibiotic gut mucosal microbiome reconstitution is impaired by probiotics and improved by autologous FMT. Cell. 2018;174(6):1406.

109. McQuade JL, Ologun GO, Arora R, Wargo JA. Gut microbiome modulation via fecal microbiota transplant to augment immunotherapy in patients with melanoma or other cancers. Curr Oncol Rep. 2020;22(7).

110. Kristensen NB, Bryrup T, Allin KH, Nielsen T, Hansen TH, Pedersen O. Alterations in fecal microbiota composition by probiotic supplementation in healthy adults: a systematic review of randomized controlled trials0. Genome Med. 2016;8(1):52. https://doi.org/10.1186/s13073-016-0300-5.

111. Rothschild D, Weissbrod O, Barkan E, Kurilshikov A, Korem T, Zeevi D, et al. Environment dominates over host genetics in shaping human gut microbiota. Nature. 2018;555(7695):210-5. https://doi.org/10.1038/nature2 5973.

112. McDonald D, Hyde E, Debelius JW, Morton JT, Gonzalez A, Ackermann G, et al. American Gut: an open platform for citizen science microbiome research. mSystems. 2018;3(3). 
113. De Almeida CV, de Camargo MR, Russo E, Amedei A. Role of diet and gut microbiota on colorectal cancer immunomodulation. World I Gastroenterol. 2019;25(2):151-62.

114. Paramsothy S, Kamm MA, Kaakoush NO, Walsh AJ, van den Bogaerde J, Samuel D, et al. Multidonor intensive faecal microbiota transplantation for active ulcerative colitis: a randomised placebo-controlled trial. Lancet. 2017; 389(10075):1218-28.

115. Goldenberg JZ, Yap C, Lytvyn L, Lo CK, Beardsley J, Mertz D, et al. Probiotics for the prevention of Clostridium difficile-associated diarrhea in adults and children. Cochrane Database Syst Rev. 2017;12(12):Cd006095.

116. Shanahan F, Quigley EM. Manipulation of the microbiota for treatment of IBS and IBD-challenges and controversies. Gastroenterology. 2014;146(6): 1554-63. https://doi.org/10.1053/j.gastro.2014.01.050.

117. Hempel S, Newberry SJ, Maher AR, Wang Z, Miles JN, Shanman R, et al. Probiotics for the prevention and treatment of antibiotic-associated diarrhea: a systematic review and meta-analysis. Jama. 2012;307(18):1959-69. https://doi.org/10.1001/jama.2012.3507.

118. Underwood MA. Probiotics and the prevention of necrotizing enterocolitis. J Pediatr Surg. 2019;54(3):405-12.

119. Soldati L, Di Renzo L, Jirillo E, Ascierto PA, Marincola FM, De Lorenzo A. The influence of diet on anti-cancer immune responsiveness. J Transl Med. 2018; 16(1):75. https://doi.org/10.1186/s12967-018-1448-0.

120. Arkan MC. The intricate connection between diet, microbiota, and cancer: a jigsaw puzzle. Semin Immunol. 2017;32(C):35-42.

121. Mehta RS, Mima K, Song M, Nishihara R, Cao Y, Qian ZR, et al. Diet and risk of colorectal Cancer according to Intratumoral Fusobacterium Nucleatum levels. Gastroenterology. 2016;150(4):S154. https://doi.org/10.1016/S00165085(16)30614-X.

\section{Publisher's Note}

Springer Nature remains neutral with regard to jurisdictional claims in published maps and institutional affiliations.

Ready to submit your research? Choose BMC and benefit from:

- fast, convenient online submission

- thorough peer review by experienced researchers in your field

- rapid publication on acceptance

- support for research data, including large and complex data types

- gold Open Access which fosters wider collaboration and increased citations

- maximum visibility for your research: over $100 \mathrm{M}$ website views per year

At $\mathrm{BMC}$, research is always in progress.

Learn more biomedcentral.com/submissions 